\title{
Polymorphism of the FABP2 gene: a population frequency analysis and an association study with cardiovascular risk markers in Argentina

\author{
Laura C Gomez ${ }^{1}$, Sebastián M Real ${ }^{1}$, Marta S Ojeda ${ }^{2}$, Sergio Gimenez ${ }^{3}$, \\ Luis S Mayorga ${ }^{1}$ and María Roqué*1
}

\begin{abstract}
Address: ${ }^{1}$ Laboratory of Cellular and Molecular Biology, Faculty of Medical Sciences, National University of Cuyo, Mendoza CP:5500, Argentina, ${ }^{2}$ Faculty of Chemistry, Biochemistry and Pharmacy, National University of San Luis, San Luis, Argentina and ${ }^{3}$ Sanatorio Fleming-OSEP, Mendoza, Argentina

Email: Laura C Gomez - lgomez@fcm.uncu.edu.ar; Sebastián M Real - sreal@unsl.edu.ar; Marta S Ojeda - msojeda@unsl.edu.ar; Sergio Gimenez - sergio.gimenez@osep.mendoza.gov.ar; Luis S Mayorga - lmayorga@fcm.uncu.edu.ar;

María Roqué* - mroque@fcm.uncu.edu.ar

* Corresponding author
\end{abstract}

Published: 26 June 2007

BMC Medical Genetics 2007, 8:39 doi: 10.1 I86/147|-2350-8-39

This article is available from: http://www.biomedcentral.com/I47|-2350/8/39

(C) 2007 Gomez et al; licensee BioMed Central Ltd.

This is an Open Access article distributed under the terms of the Creative Commons Attribution License (http://creativecommons.org/licenses/by/2.0), which permits unrestricted use, distribution, and reproduction in any medium, provided the original work is properly cited.

\begin{abstract}
Background: The FABP2 gene encodes for the intestinal FABP (IFABP) protein, which is expressed only in intestinal enterocytes. A polymorphism at codon 54 in exon 2 of the FABP2 gene exchanges an Alanine (Ala), in the small helical region of the protein, for Threonine (Thr). Given the potential physiological role of the Ala54Thr FABP2 polymorphism, we assess in this study the local population frequency and analyze possible associations with five selected markers, i.e. glycemia, total cholesterol, body mass index (BMI), hypertension, and high Cardiovascular Risk Index (CVR index).
\end{abstract}

Methods: We studied 86 men and 116 women. DNA was extracted from a blood drop for genotype analysis. Allele frequencies were calculated by direct counting. Hardy Weinberg Equilibrium was evaluated using a Chi-square goodness of fit test.

For the polymorphism association analysis, five markers were selected, i.e. blood pressure, Framingham Risk Index, total cholesterol, BMI, and glycemia.

For each marker, the Odds Ratio (OR) was calculated by an online statistic tool.

Results: Our results reveal a similar population polymorphism frequency as in previous European studies, with $\mathbf{q}=\mathbf{0 . 2 7 7}$ ( $95 \%$ confidence limits $0.234-0.323$ ). No significant association was found with any of the tested markers in the context of our Argentine nutritional and cultural habits. We did, however, observe a tendency for increased Cholesterol and high BMI in Thr54 carriers.

Conclusion: This is the first study to look at the population frequency of the Thr54 allele in Argentina. The obtained result does not differ from previously reported frequencies in European populations. Moreover, we found no association between the Thr54 allele and any of the five selected markers. The observed tendency to increased total cholesterol and elevated BMI in Thr54 carriers, even though not significant for $\mathrm{p}<0.1$ could be worth of further investigation to establish whether the Thr54 variant should be taken into consideration in cardiovascular prevention strategies. 


\section{Background}

Fatty acid-binding proteins (FABPs) are small intracellular polypeptides found in many tissues, involved in fatty acid transfer and metabolism [1] and encoded by a family of different genes. The FABP2 gene encodes intestinal FABP protein (IFABP), and is only expressed in the absorptive simple columnar epithelial cells of the intestine (enterocytes) [2]. Several functions of IFABP protein have been proposed, these include the facilitation of cellular uptake and/or transport of long-chain fatty acids within enterocytes [3]. The IFABP protein contains two beta-sheet structures surround a cavity into which the ligand binds [4]. The major conformational adjustment between the structure of free IFABP and IFABP bound to fatty acid, occurs at a tight turn containing residues 54 and 55 . These residues shift position when long-chain fatty acids are bound to the protein. Therefore, even a subtle change in the amino acid sequence of this turn could affect the structural properties of IFABP in such a way as to alter its ligand affinity [5].

A polymorphism at codon 54 in exon 2 of the human FABP2 gene exchanges an Alanine (Ala) in the small helical region of the protein for Threonine (Thr). Different studies suggest that the Ala-to-Thr substitution is in fact a functional mutation $[6,7]$. It is reasonable to speculate that if the FABP2 gene polymorphism in any way modifies the absorption of fatty acids, it could in turn affect the lipid metabolism and/or correlate with cardiovascular disease (CVD) risk. Earlier studies have shown that the IFABP Thr54 allele is significantly associated with higher total cholesterol, with stroke incidence [8], elevation of fasting and postprandial triglyceride [9], insulin resistance $[2,6]$, and higher nonesterified fatty acid (NEFA) concentrations [10]. There are many contradicting studies, however, that have found non-significant association with these parameters [11-14]. In the light of the potential physiological role of the FABP2 polymorphism, we assessed the local population frequency of the Thr54 allele and analyzed its possible associations with five selected markers, i.e. glycemia, total cholesterol, body mass index (BMI), hypertension and cardiovascular risk index (CVR index). Our results reveal a similar population polymorphism frequency as in previous European studies and a not significant association with none of the tested markers in the context of our argentine nutritional and cultural habits.

\section{Methods}

\section{Subjects}

We recruited 202 volunteers (mean age 53 years) from various Public Administration Offices, including 86 men (aged between 35 and 75 years, mean age 51) and 116 women (aged between 45 and 75 years, mean age 56). The means in the sample were: cholesterol level 198,34 (190,52 for men and 204,27 for women), diastolic blood pressure: 79,38 ( 82,93 for men and 76,96 for women), systolic blood pressure: $127,22(131,15$ for men and 124,26 for women) and BMI: 28,45 (28,86 for men and 28,13 for woman). In the 202 subjects, there were only 11 diabetics. On receiving written informed consent from all participants included in this population screening study, a drop of blood was collected for total cholesterol and glycemia analysis using commercial kits (Accu-Chek Instant Plus, Roche Diagnostic). A second drop of blood was collected on a DNAase free paper (Nucleic Paper, Biodynamics S.R.L, Buenos Aires, Argentina) for DNA extraction. Systolic and diastolic blood pressure was measured by a physician. BMI was calculated as weight $(\mathrm{kg})$ divided by height squared $\left(\mathrm{m}^{2}\right)$. The ethical committee of the Public Health Care Program for Government Employees (OSEP, Obra Social del Empleado Publico) approved the study.

\section{Cardiovascular risk assessment by calculation of the Framingham Risk Index}

The cardiovascular risk was calculated for each individual by the Framingham Index according to the National Cholesterol Education Program (NCEP) Adult Treatment Panel (ATP) III guidelines [15]. This index takes into account the following variables: sex, age, blood pressure, total cholesterol, HDL and smoking status. The HDL measure was excluded from this study because of its low impact on the total score for the risk calculation. The total score was obtained by summing the partial scores for each of the variables mentioned. The total score of 10 was established as the threshold, with a 0 to 9 total score implying low risk status and a 10 or higher total score implying high risk status.

\section{Genotype analysis}

To extract DNA, a piece of $2 \mathrm{~mm}$ radio was cut out from the blood drop on DNAse free paper, added to $100 \mu \mathrm{l}$ sterile water, and then incubated for 30 minutes at $95^{\circ} \mathrm{C}$. For PCR reaction $10 \mu \mathrm{l}$ were used. Some DNA samples which did not amplify well were diluted 1:10 or 1:20.

DNA was amplified in a total volume of $20 \mu \mathrm{l}$, with the upstream primer: 5'ACAGGTGTTAATATAGTGAAAAG3' and the downstream primer: $5^{\prime}$ TACCCTGAGTTCAGTTCCGTC3' [6]. The PCR program consisted of an initial and final hold of $94^{\circ} \mathrm{C}$ and $72^{\circ} \mathrm{C}$ for 3 minutes, and 30 cycles of $94^{\circ} \mathrm{C}, 55^{\circ} \mathrm{C}$, and $72^{\circ} \mathrm{C}$, with each step of 30 seconds duration.

For Restriction Fragment length Polymorphism (RFLP) analysis, $5 \mu \mathrm{l}$ of PCR product were incubated with $0.4 \mu \mathrm{l}$ of enzyme CfoI (GCG/C) (10 U/ $\mu \mathrm{l}$, Promega) in a final volume of $10 \mu \mathrm{l}$ for 1 hour at $37^{\circ} \mathrm{C}$. 
The products were run on a $10 \%$ non-denaturing PAGE for 50 minutes at $110 \mathrm{~V}$. Bands were observed after Ethidium bromide staining and UV light exposure.

\section{Allele frequency and polymorphism association analysis} Allele frequencies were calculated by direct counting. Hardy Weinberg Equilibrium was evaluated using a Chisquare goodness of fit test.

For the polymorphism association analysis, five markers were selected, i.e. blood pressure, Framingham Risk Index, total cholesterol, BMI, and glycemia. Each parameter was assigned a threshold value, established by the RCP Program, as follows:

1-Hypertension >140 mmHg systolic or >90 $\mathrm{mmHg}$ diastolic; 2-Framingham Risk Index $>9$ total score; 3-BMI $>24 \mathrm{~kg} / \mathrm{m} 2$; 4-Total cholesterol > $240 \mathrm{mg} /$ dl; 5-Glycemia $>110 \mathrm{mg} / \mathrm{dl}$ after $8 \mathrm{~h}$ fasting or $>140 \mathrm{mg} / \mathrm{dl}$ postprandial.

For each marker, the Odds Ratio (OR) was calculated by the online statistic tool [16].

\section{Results}

\section{The Thr54 allele frequency in Argentina}

To assess the polymorphism frequency in our region, DNA samples of 202 individuals (86 men and 116 women) were analyzed for the Ala/Thr polymorphism. The included subjects belonged to an ongoing Regional Cardiovascular Prevention Program (RCP program), organised by the Public Health Care Program for Government Employees (OSEP) of Mendoza (Argentina). This programme focuses on the assessment of an individual cardiovascular risk index in order to apply prevention strategies in the analyzed population.

The observed population genotype composition was: 105 Ala/Ala homozygous, $82 \mathrm{Ala} / \mathrm{Thr}$ heterozygous and 15 Thr/Thr homozygous (Table 1).

Eventhough the province of Mendoza has a total population of almost 1.600 .000 individuals, it presents a nonhomogenous population distribution provoked by the migration of families to the surroundings of the capital city of Mendoza. We therefore decided to carefully analyze our genotype composition results in order to detect whether our sample could be affected by endogamic behaviour. The cluster of inhabitants around the city could lead to inbreeding and consequently reduce the number of observed homozygous, and affect the allele frequency. In order to assess whether this was interfering with our population sample, the amount of observed heterozygous and homozygous for the Ala54Thr polymorphism was used in the formula $\mathrm{F}=\mathrm{He}-\mathrm{Ho} / \mathrm{He}$ (where He and Ho are expected and observed heterozygous). How- ever, a negative (-) 0,02 inbreeding rate was found, confirming there is no endogamic behaviour in our population that could have affected the allele frequency.

The calculated Thr54 allele frequency was $\mathbf{q}=\mathbf{0 . 2 7 7}(95 \%$ confidence limits $0.234-0.323$ ). In a subsequent analysis of the equilibrium of the populations genotypes, the results revealed that the proportion of hetero and homozygous did not differ significantly from the expected genotypes for a population in Hardy Weinberg equilibrium (Table 1) ( $\mathrm{p}>0.05$, Chi squared goodness of fit), which is consistent with our first finding of non-endogamic behaviour.

The assessment of the polymorphism frequency in Argentina with similar values as in European countries [17] encouraged us to subsequently analyze possible genotype-phenotype associations.

\section{Polymorphism association analysis reveals no significant impact on CVD risk markers}

For the genotype-phenotype association assessment, the phenotypic information of the 202 individuals included in the study was used. Association analysis with allele Thr54 was performed on five selected parameters, i.e. glycemia, total cholesterol, BMI, hypertension, and cardiovascular risk (calculated by the Framingham Risk Index). Comparisons were performed between subjects that carried at least one Thr54 allele (homozygous Thr/Thr and heterozygous Ala5Thr) and non-carriers of the allele Thr54 (homozygous Ala/Ala). For each parameter, a threshold value was established by the RCP Program (see Methods).

Our study reveals no significant association ( $p>0.05$ ) between the Thr54 allele and any of the analyzed parameters (Table 2). The ORs represent the magnitude of association between the genotype and disease, consequently ORs with a 95\%CI including the value 1 are indicative of no difference between Thr54 carriers and non-carriers for that factor. We analysed the five markers in male Thr54 carriers respect to female Thr54 carriers. We did not find any significant difference (for $\mathrm{p}=0,05$ ) between gender for BMI, cholesterol, blood pressure, and glycemia.

These results are in accordance with other previous publications that found no major contribution of allele Thr54 on these phenotypic parameters [11-14].

Despite the non-significant association results, we consider it worth noting that the ORs for Cholesterol (2.01), BMI (1.44) and CVD risk (1.25) are $>1$. When we analyzed the distribution of Thr54 carriers and non-carriers combining two of these three parameters, we observed an increased number of polymorphism carriers with high 
Table I: Genotype analysis in the study subjects

\begin{tabular}{lccc}
\hline & Homozygous Ala54/Ala54 & Homozygous Ala54/Thr54 & Homozygous Thr54/Thr54 \\
\hline Observed number & 105 & 82 & 15 \\
Expected number & 105.5 & 81 & 15.5 \\
\hline
\end{tabular}

$X^{2}$ n.s. $p>0.05 q(T h r 54)=0.2777(95 \% \mathrm{Cl}: 0.234-0.323)$ Sample size: 202

In a sample of 202 individuals, genotype analysis was performed for the polymorphism Ala/Thr. The observed number of homozygous and heterozygous was not significantly different from that expected in a population in Hardy Weinberg Equilibrium. The Thr54 frequency found in the Argentine populations was $q=0.277$.

cholesterol and high BMI (Figure 1). Notice in Figure 1a that the quadrant corresponding to high cholesterol and high BMI shows more carrier individuals (17/97) than non-carriers (10/105). This not significant difference for $\mathrm{p}$ $<0.1$ but subtle tendency was not observed in the rest of the parameter combinations that were analyzed (data not shown). These results reveal that even though the markers for Cholesterol and BMI do not show a significant association with the polymorphism when they are analyzed on their own, a subtle tendency is observed when they are analyzed in combination.

\section{Discussion}

There are no previous reports about the prevalence of the Thr54 FABP2 variant in our region. In the sample tested, the observed Thr54 frequency $(q=0,277)$ is similar to that reported in eleven different European countries (0.276) [17], suggesting that the colonising European populations, mainly from Italy and Spain, introduced the same original allele frequency in this continent and that this frequency has remained conserved. The fact that the proportion of carriers has not changed and that the polymorphism is in a Hardy Weinberg equilibrium suggests that there is no significant natural selection pressure acting against individuals with the Thr54 FABP2 variant living in Mendoza, Argentina. Other South American frequency analysis of Thr54 were reported by a Chilean group, who found a $\mathrm{q}=0.4$ in 63 obese and not obese women [18], and a Brazilian study that reported a $\mathrm{q}=0.25$ in 1042 diabetes type 2 individuals [19]. Even though both analyses are performed on specific study sample, i.e. obese and diabetic individuals, the Brazilian frequency in 1042 individuals is similar to that observed by our group in Argentina.

It is well known that the single nucleotide polymorphism (SNP) at codon 54 is a missence variant that has a definite effect on the primary structure of the protein and affects its fatty acid binding properties. It is not known, however, whether this change can affect the lipid metabolism of carriers [20]. Many earlier studies have reported associations between this polymorphism and insulin resistance, BMI, dyslipidemia, stroke, metabolic syndromes and hypertriglyceridemia [2,6,8-10,21-23]. In contrast, other studies report no association with the same parameters [11-14]. Part of the discrepancy among the studies may come from the different dietary habits of the analyzed populations. For example, the lack of association found in a Finnish population [24] could be related to its prevailing fish diet where the Thr54 variant may not cause any phenotypical manifestation. Therefore, it was important to assess some of these associations in Argentina, characterized by the consumption of significant amounts of beef (i.e. $68 \mathrm{~kg}$ of beef/year/habitant). This diet is rich in proteins and fats and poor in fibres and fish [25]. In addition, it was relevant for the local RCP Program to develop health preven-

Table 2: Association analysis of the Thr54 polymorphism and phenotypic parameters

\begin{tabular}{|c|c|c|c|}
\hline Phenotypic parameters and threshold values & OR & $C l(p=0.05)$ & Significance \\
\hline Cholesterol > $240 \mathrm{mg} / \mathrm{ml}$ & 2.01 & $0.87-4.65$ & NS \\
\hline $\mathrm{BM} />24 \mathrm{~kg} / \mathrm{m} 2$ & 1.44 & $0.7-2.98$ & NS \\
\hline Cardiovascular risk $>9$ & 1.25 & $0.62-2.5$ & NS \\
\hline Diastolic blood pressure $>90 \mathrm{mmHg}$ & 0.93 & $0.51-1.69$ & NS \\
\hline Systolic blood pressure > $140 \mathrm{mmHg}$ & 0.86 & $0.44-1.47$ & NS \\
\hline Glycemia $>140 \mathrm{mg} / \mathrm{dl}$ postprandial & 0.76 & $0.33-1.76$ & NS \\
\hline
\end{tabular}

ORs were calculated as ratio between polymorphism carriers and non-carriers with high blood pressure $(>140 \mathrm{mmHg}$ systolic or $90 \mathrm{mmHg}$ diastolic), high Framingham Risk Index (>9) high cholesterol (>240 mg/dl), high BMI (>24 kg/m2), and high glycemia (>1 $10 \mathrm{mg} / \mathrm{dl}$ after $8 \mathrm{~h}$ fasting or $>140$ postprandial $\mathrm{mg} / \mathrm{dl}$ ). $95 \%$ Confidence Intervals for $\mathrm{p}=0.05$ are shown. All $\mathrm{Cl}$ include $\mathrm{OR}=\mathrm{I}$, indicating no significant association between the polymorphism and the parameters tested. 

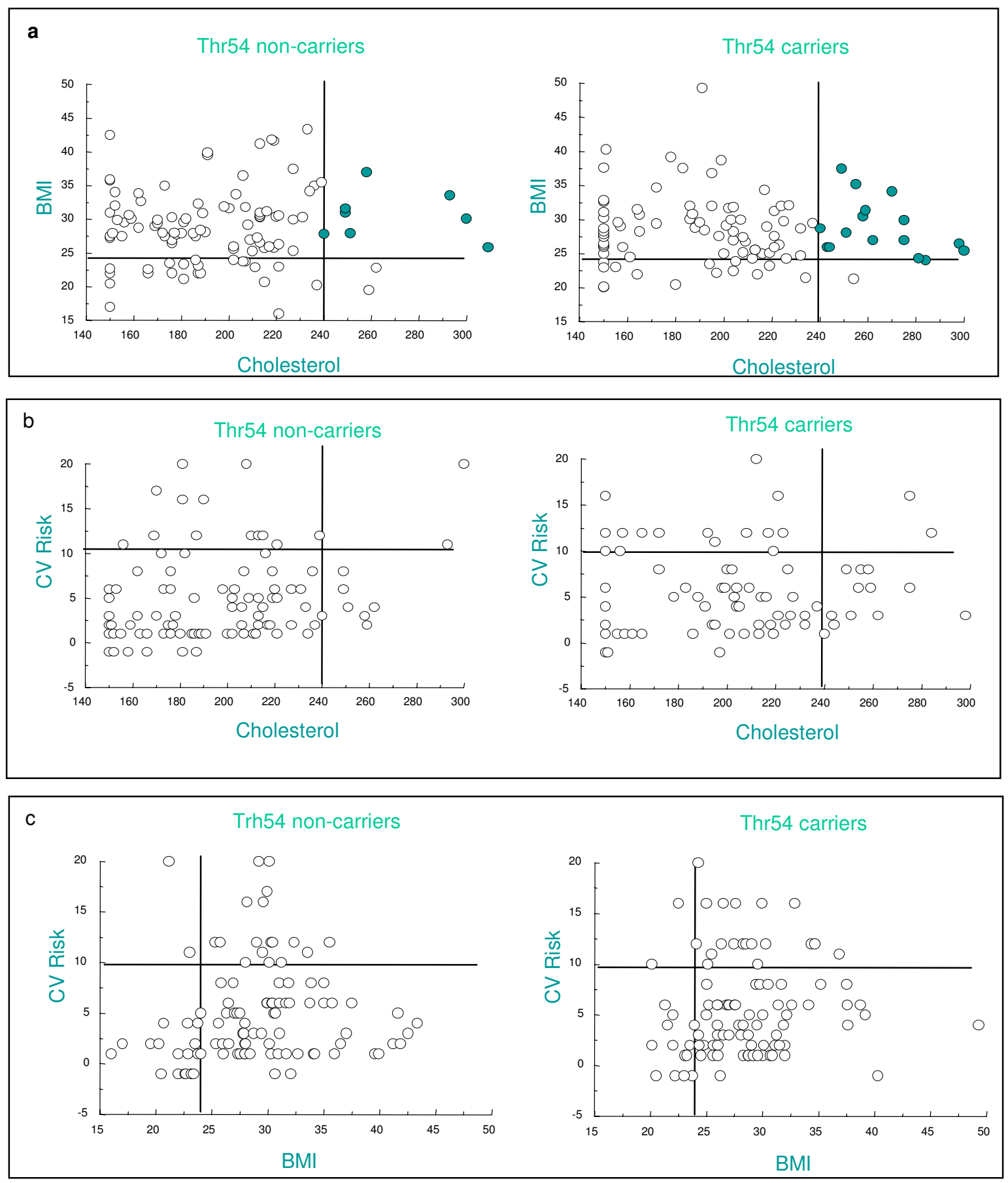

\section{Figure I}

Association of Thr54 carriers with the combination of markers: i.e. cholesterol, BMI and cardiovascular risk index. Sample distribution for Thr54 carriers (homozygous Thr/Thr and heterozygous Ala/Thr) and non-carriers (homozygous Ala/Ala) regarding two features: (a) BMI and Choslesterol (b) Cardiovascular risk index (CV Risk) and Cholesterol. (c) Cardiovascular risk index (CV Risk) and BMI. The crossing lines show the threshold values for BMI ( $24 \mathrm{~kg} / \mathrm{m} 2)$, cholesterol $(220 \mathrm{mg} /$ $\mathrm{dl})$, and high risk (9 total score) 
tion strategies based on educational programs of life style and nutritional habits.

Our results indicate that in the assessed population, the allele Thr54 does not influence the glycemia levels nor the blood pressure (odds ratio approaching 1).

The Cholesterol levels, BMI and CVR index are not significantly influenced by the Thr 54 , but show ORs $>1$. These tendencies for increased risk are better manifested when BMI and Cholesterol are analysed in a combination. This observation does, however, not prove association or causality. The sample size was small, and these observed tendencies require further investigation in order to reveal whether the influences become significant and whether it could be related to the meat and fat-rich diet prevailing in Argentina.

\section{Conclusion}

We present the first study investigating the Thr54 allele frequency in Argentina and its association with five cardiovascular risk markers. The population frequency of the Thr54 allele in Argentina does not differ from previously reported frequencies in European populations. Moreover, we found no association between the Thr54 allele and any of the five selected markers. Although the observed tendency for increased total cholesterol and elevated BMI in Thr54 carriers was not significant, this will require further investigation to establish whether the Thr54 variant should be taken into consideration in cardiovascular prevention strategies in our country.

\section{Competing interests}

The author(s) declare that they have no competing interests.

\section{Authors' contributions}

LCG performed the DNA sampling, the molecular assays, the frequency analysis, the phenotypic association studies and the revision of the manuscript. SMR contributed to the DNA sampling and the genotyping experiments. MSO provided the original idea and the PCR primers set. SG is the head of the RCP Program. LSM advised on the design of the study, on the experimental work, and on the critical revision of the manuscript. MR developed and guided the project and drafted the manuscript. All authors read and approved the final manuscript.

\section{Acknowledgements}

This work was supported by the Public Health Care Program for Government Employees (OSEP, Obra Social del Empleado Publico) Mendoza, Argentina.

\section{References}

I. Hsu KT, Storch J: Fatty Acid Trasfer from liver and Intestinal Fatty-bindig Proteins to Membranes Occurs by Differents Mechanisms. J Biol Chem 1996, 27 I: I33 I7-13323.

2. Weiss EP, Brown MD, Shuldiner AR, Hagberg JM: Fatty Acid binding protein-2 gene variants an insulin resistance: gene and gene-environment interaction effects. Physiol Genomics 2002, 10:145-157.

3. Berthier MT, Couillard C, Prud'homme D, Nadeau A, Bergeron J, Tremblay A, Depre's JP, Vohl MC: Effects of the FABP2 A54T Mutation on Triglyceride Metabolism of Viscerally Obese Men. Obesity Research 200I, 9:668-675.

4. Rajabzadeh M, Kao J, Frieden C: Consequences of single-site mutations in the intestinal fatty acid binding protein. Biochemistry 2003, 42:12192-12199.

5. Zhang F, Lucke C, Baier L, Sacchettini JC, Hamilton JA: Solution structure of intestinal fatty acid binding protein: Implications for ligand entry and exit. Journal of Biomolecular NMR I997, 9:213-228.

6. Baier LJ, Sacchettini JC, Knowler WC, Eads J, Paolisso G, Tataranni PA, Hisayoshi M, Bennett PH, Bogardus C, Prochazka M: An amino acid substitution in the human fatty acid binding protein is associated with increased fatty acid binding, increased fat oxidation and insulin resistance. J Clin Invest 1995, 34:249-266.

7. Baier LJ, Bogardus C, Sacchettini JC: A polymorphism in the human intestinal fatty-acid-binding protein alters fatty acid transport across Caco-2 cells. I Biol Chem 1996, 27 I: $10892-10896$.

8. Carlsson M, Orho-Melander M, Hedenbro J, Almgren P, Groop LC: The T54 Allele of the Intestinal Fatty Acid-Binding protein 2 is associated with a parental history of stroke. J Clin Endocrinol Metab 2000, 85:2801-2804.

9. Georgopoulos A, Aras O, Tsai MY: Codon-54 polymorphism of the fatty acid-binding protein 2 gene is associated with elevation of fasting and postprandial triglyceride in type 2 diabetes. J Clin Endocrinol Metab 2000, 85:3155-3160.

10. Pratley RE, Baier L, Pan DA, Salbe AD, Storlien L, Ravussin E, Bogardus C: Effects of an Ala54Thr polymorphism in the intestinal fatty acid-binding protein on responses to dietary fat in humans. J Lipid Res 2000, 41:2002-2008.

II. Galluzzi JR, Acupples L, Meigs JB, Wilson PW, Schaefer EJ, Ordovas JM: Association of the Ala54-Thr polymorphism in the intestinal fatty acid-binding protein with $2-h$ postchallenge insulin levels in the Framingham Offspring Study. Diabetes Care 200I, 24: I I6I-II66.

12. Endo K, Yanagi H, Hirano C, Hayakawa Y, Hamaguchi H, Tomura S: No association found between the Ala54Thr polymorphism of FABP2 gene and obesity and obesity with dyslipidemia in Japanese schoolchildren. J Atheroscler Throm 2001, 8:80-83.

13. Pihlajamaki J, Rissanen J, Heikkinen S, Karjalainen L, Laakso M: Codon 54 polymorphism of the human intestinal fatty acid binding protein 2 gene is associated with dyslipidemias but not with insulin resistance in patients with familial combined hyperlipidemia. J Clin Endocrinol Metab 2002, 87:3735-3739.

14. Erkkila AT, Lindi V, Lehto S, Pyorala K, Laakso M, Uusitupa MI: Variation in the fatty acid binding protein 2 gene is not associated with markers of metabolic syndrome in patients with coronary heart disease. Nutr Metab Cardiovasc Dis 2002, I 2:53-59.

15. National Cholesterol Education Programme (NCEP) Adult Treatment Panel (ATP) III guideline [http://www.nhlbi.nih.gov/ guidelines/cholesterol/atglance.pdf]

16. Pedro Confidence Interval Calculator: [http:// www.pedro.fhs.usyd.edu.au/calculator.html].

17. Tahvanainen E, Molin M, Vainio S, Tiret L, Nicaud V, Farinaro E, Masana L, Ehnholm C: Intestinal fatty acid binding protein polymorphism at codon 54 is not associated with postprandial responses to fat and glucose tolerance tests in healthy young Europeans. Results from EARS II participants. Atherosclerosis 2000, I 52:317-325.

18. Albala C, Santos JL, Cifuentes M, Villaroel AC, Lera L, Liberman C, Angel B, Perez Bravo F: Intestinal FABP2 A54T polymorphism: association with insulin resistance ana obesity in women. Obesity Res 2004, I 2:340-345.

19. Canani LH, Capp C, Ng DPK, Choo SGL, Maia AL, Nabinger GB, Santos K, Crispim D, Roisemberg I, krolewski AS, Gross JL: The fatty acid binding protein 2 A54T polymorphism is associated 
with renal disease in patients with type 2 daibetes. Diabetes 54:3326-3330.

20. Agren Jj, Valve R, Vidgren H, Laakso M, Uusitupa M: Posprandial lipemic response is modified by the polymorphism at codon 54 of the fatty acid-binding protein 2 gene. Arterioscler Thromb Vasc Biol 1998, 18:1606-1610.

21. Hegele RA, Harris SB, Hanley AJ, Sadikian S, Connelly PW, Zinman B: Genetic variation of intestinal fatty acid-binding protein associated with variation in body mass in aboriginal Canadians. J Clin Endocrinol Metab 1996, 8 I:4334-4337.

22. Guettier JM, Georgopoulos A, Tsai MY, Radha V, Shanthirani S, Deepa R, Gross M, Rao G, Mohan V: Polymorphisms in the fatty acidbinding protein 2 and apolipoprotein C-III genes are associated with the metabolic syndrome and dyslipidemia in a South Indian population. J Clin Endocrinol Metab 2005, 90: $1705-17 \mid 1$.

23. Vimaleswaran KS, Radha $\mathrm{V}$, Mohan $\mathrm{V}$ : Thr54 allele carriers of the Ala54Thr variant of FABP2 gene have associations with metabolic syndrome and hypertriglyceridemia in urban South Indians. Metabolism 2006, 55: I222-1 226.

24. Rissanen J, Pihlajamäki J, Heikkinen S, Kekäläinen P, Kuusisto J, Laakso $\mathrm{M}$ : The Ala54Thr polymorphism of the fatty acid binding protein 2 gene does not influence insulin sensitivity in Finnish nondiabetic and NIDDM subjects. Diabetes 1997, 46:7| I-7|2.

25. Navarro A, Diaz MP, Munoz SE, Lantieri MJ, Eynard AR: Characterization of meat consumption and risk for colorectal cancer in Cordoba, Argentina. Nutrition 2003, 19:7-10.

\section{Pre-publication history}

The pre-publication history for this paper can be accessed here:

http://www.biomedcentral.com/1471-2350/8/39/prepub

Publish with Biomed Central and every scientist can read your work free of charge

"BioMed Central will be the most significant development for disseminating the results of biomedical research in our lifetime. "

Sir Paul Nurse, Cancer Research UK

Your research papers will be:

- available free of charge to the entire biomedical community

- peer reviewed and published immediately upon acceptance

- cited in PubMed and archived on PubMed Central

- yours - you keep the copyright 